\title{
VERSITA
}

DOI: $10.2478 / \mathrm{abcsj}-2013-0004$

\section{Character as a Vanishing Point in American Experimental Fiction}

\author{
SALWA KAROUI-ELOUNELLI \\ University of Sousse
}

\begin{abstract}
"I take their souls away-I know it- and I play with them; I puppet them up to something; I march them through strange crowds and passions; I snuffle at their roots."

William Gass, "Mrs. Mean” 83
\end{abstract}

\begin{abstract}
My paper discusses the construction of character in some American experimental narratives within the optical paradigm of the vanishing point. In a first part the investment of the pictorial notion of the vanishing point in Faulkner's Light in August will be discussed as an instance of the occasional confrontation in Modernist fiction of the limits of literary representation, even if the pictorial category is adapted (and so limited) to the specific issue of biracial identity. In a second part, William Gass's short story "Mrs. Mean" and Paul Auster's The Locked Room will be examined as instances of a sustained critical recasting of the very concept of character. The trope of the vanishing point is consciously deployed in both texts to reinvent fictional character within the challenging scope of borderlines between presence and absence, the life-like (mimetic) and the purely verbal.
\end{abstract}

Keywords: Modernism, Postmodernism, characterization and character in fiction, pictorial language, vanishing point, literary representation, William Faulkner, Paul Auster, William Gass

The strategies of characterization in experimental fiction often amount to the foregrounding of an ironical (even self-defeating) re-negotiation of the very concept of character. In Postmodern poetics more specifically, such re-negotiation often consecrates a sustained questioning of the very limits 
of literary representation. Among the aspects of the problematization of character, there are those that emanate from the tendency of some experimental fictional narratives to invest the scope of perception in their implicit critique of the mimetic force of literary representation. The aim of this paper is to discuss some facets of the process through which the mimetic content of characterization is dismantled or polemicized within a paradoxical investment of the pictorial paradigm by some American fictional narratives.

The appeal to the pictorial paradigm of the visual arts in the fictional narratives selected in the present work illustrates an aspect of the continuity between the experimental dimension of the Modernist and Postmodernist fiction, but also the intensity that such experimentation acquires, more specifically, in Postmodernist narratives. In the narratives examined here, namely Light in August by William Faulkner, "Mrs. Mean" by William Gass, and The Locked Room by Paul Auster, the pictorial paradigm informs and deconstructs the process of character portrayal through the appeal that those fictional texts make to the specific category of the vanishing point. The pictorial notion of the vanishing point attests to a particular form of appropriation of the pictorial aesthetics to verbal art: it bespeaks the concern of experimental fiction with reinventing the narrative convention of character as a representational limit. The paradoxical nature of such appropriation has to do with the fact that the pictorial model is reshaped in experimental literary narrative within a sustained amplification and undermining of the perceptual scope/ effect.

Indeed, the visual category of the vanishing point is adapted to the self-critical, self-questioning tendency of the Modernist and Postmodernist American fiction in ways that enhance its aesthetics of paradox. That is, the trope of the vanishing point implies an appeal to the optical illusions of the pictorial paradigm for the purpose of problematizing the convention of character portrayal. That problematization of conventional characterization emanates from the association between character and the "unpresentable" that the effect of the vanishing point sustains in the fictional narrative.

The play of the pictorial paradigm and its border category of the vanishing point in William Faulkner's Light in August, William Gass's 
"Mrs. Mean" and Paul Auster's The Locked Room may illustrate, as this paper argues, a significant aspect of continuity but also of rupture between the processes and implications of characterization in the Modernist and the Postmodernist poetics. The rupture has to do with the fact that the critique of representation implied in the creation of character along the line of the vanishing point reaches a more radical degree in the Postmodernist than in the Modernist narratives.

In the fields of narratology and fiction criticism, theories of character have been articulated within approaches that either stress the mimetic content of fictional narrativity or the structural operation of narrative textuality. Thus, characters have been conceptualized in the critical and theoretical discourse through the term of "persons" (emphasizing the "human-like" dimension of the fictional convention) or through the notion of function (structuralist notions like "actant" or "actor" have stressed the rootedness of character in the totality of the narrative fabric). Some critics have insisted on the peculiar status that character, among the conventions of narrative fiction, enjoy. Brian Phillips (2004: 633) posits that among the literary effects of the components of fiction, character is the most likely "to break free from words"; we remember fictional character not as part of the textual fabric but as "separable beings." This quality seems to resist the increasing problematization of character in contemporary experimental fiction. Phillips has rightly pointed to the significant link between the questioning of the possibility of knowing the others ("the (un)knowability of character") and the tendency of contemporary fiction to "flatten" character: the denial of conventional complexity and depth in character portrayal is actually an undermining of the possibility of knowing the others. What is noticeable in the critical literature on character, is that the current theoretical delineations have approached the concept of character less in relation to the problematical issue of knowledge, than in relation to the thorny concepts of identity and selfhood. My aim is to explore the relevance of some of theoretical findings to the poetics of some experimental fictional narratives that invest the visual paradigm in their strategies of characterization.

In more recent critical revisions of character theory, some studies 
like Geni Babb's (2002: 201) have pointed to the fact that the narratological approaches have excluded the dimension of the body in their analysis of character or reduced it to the level of "ornamental" description; character being mainly theorized in terms of action or consciousness. Babb accounts for this predominant tendency to disregard the body when theorizing character by the influence of the Cartesian vision of bodies "as discursive objects limited to descriptions of external physical features" (201). In the model of "embodiment" that Genie Babb develops, a model that builds on the concept of "lived body" by integrating the corporeal into the theorizing of character, a particular significance is assigned to the "aspects of bodily experience that are available to conscious awareness" (203) and those that remain beyond it. The merit of Babb's work (at least as far as my study is concerned) is that it recognizes and explores the paradoxical nature of embodiment: the bodily experience often involves a movement of consciousness away from the body. This is explained by the mechanisms of perception "whereby awareness of the sense organ is "lost" or subsumed in awareness of the object of sensation"; embodiment is thus experienced as "simultaneous presence and absence" (Babb 203).

In much of experimental fiction this paradoxical nature of embodiment is invested in the narrative method so as to challenge the concept of character (more than merely reformulating it) by exploiting the ambiguity of the borderline between presence and absence. In those narratives that experiment in particular with the convention of characterization, the bodily experience or bodily dimension of a portrayed character is sometimes amplified or emphatically distorted, not to assert the primacy of consciousness or of the abstract notion of self, but to put into question the whole representational process. Such questioning acquires a particular intensity when the paradox of embodiment is reinforced by a pictorial paradox: that of the vanishing point.

The appeal to the pictorial field in the representational process of verbal art is usually expected to sustain the mimetic orientation of literature (fiction in particular) through a visual effect. And yet, the specific pictorial category of the vanishing point inspires experimental fiction with the rich paradox of challenging visibility via a visual notion; 
questioning representation through the implementation of the representational processes and categories of narrative fiction, namely character construction. The vanishing point has been described as representational gap and limit that organizes the visual field (Sorensen 2007: 433); it is an absence that is "implicated in optical illusions" (434) as "the edge of my visual field" (435). Its adaptation to the verbal process of fictional characterization is often associated with the testing of the limits of representation. When the trope of the vanishing point is fused with a self-conscious highlighting of the paradox of embodiment (as presence-absence) in experimental Postmodern fiction, the outcome is often a deep questioning of the essentialist concept of character (the conception of character that closely links the fictional category with notions of identity and self). Indeed, within the poetics of Postmodern fiction specifically, the paradigm of the vanishing point acquires an additional implication that has to do with the sustained questioning of the concepts of self and identity.

The Vanishing Point as a Model for Characterization: Light in August

In Faulkner's novel Light in August (1932), the profusion of pictorial and photographic imagery is quite central to the portrayal of Joe Christmas. The Faulknerian character is constantly bounded to a pattern of flight and of clandestinity, which is strongly implicated in the dilemma of Joe's biracial belonging. It is quite significant that beyond the tension and destructiveness that emanate from Joe's hybridity, the portrayal of the Faulknerian character attests also to a literary (representational) tension that relates to the Modernist aesthetics. The subplot that revolves around the growth and life experience of Joe Christmas is marked by the tension of the two competing ends: the conventional end that brings a sense of closure to the narrative through the motif of tragic death and the end that corresponds to the gradual dissolution of the conventional sense of character. While the former allows for the persistence of the mimetic orientation of the Faulknerian narrative, the latter displays the tendency of 
Late Modernist fiction to test the limits of literary representation. Consequently, the portrait of Joe Christmas problematizes the novelistic convention of characterization by repeatedly subverting the sense of self and identity that have traditionally furnished fictional character with a human-like, mimetic effect. Such problematization is enacted mainly within the condition of constant escape and hiding assigned to Joe. As he moves to his tragic end (in the complex order of the plot), a range of pictorial metaphors come to highlight Joe's fugitive condition, often in a way that renders polemical the whole process of characterization.

In the scene when Joe emerges from the woods in one of his nightly visits to Miss Burden and has some car lights falling upon his body, he is described through the metaphor of the photograph's negative print: "he watched his body grow white out of the darkness like a Kodak print emerging from the liquid" (82). The image is explained by Joe's position in his white underwear with the darkness in his background, but it also announces the effect of the vanishing point on which relies the whole strategy of character portrayal (as far as Joe Christmas is concerned). The image of the photographic negative with its connotation of reversal points to the perversity of Joe's racial identity (with his blackness articulated as a verbal construct rather than a biological condition). But ironically enough, the photographic metaphor becomes an announcement of the character's disappearance rather than a prelude to his emergence as authentic self. Later, when Joe begins to be totally entrapped in the condition of running away, the character is assimilated to a picture drawn in chalk (a picture that is likely to be erased):

...running on up the stairs, vanishing as he ran, vanishing upward from the head down as if he were running head first and laughing into something that was obliterating him like a picture in chalk being erased from a blackboard. (157)

This is the moment when Joe commits the first irrevocable act of violence (the aggression of his adopted father, Simon McEachern). The image of the character being "erased" like a picture in chalk does not merely announce the tragic death that Joe would face; more significantly it condenses the whole dilemma of biracial identity in Southern culture 
which mounts to no identity at all. The image of the picture drawn in chalk, like that of the photographic negative, reinforces thus the paradoxical nature of the whole process through which the perceptual field is invested in Faulkner's narrative to problematize the mimetic orientation of fictional characterization. We consider this paradox as part of the novel's attempt to highlight from within the stylistic and narrative method the polemical issue of multiracial identity (particularly in Southern American culture). The portrayal of Joe Christmas within the paradigm of the vanishing point may be interpreted as part of the ambiguous and challenging condition generated by the multiracial situation. In a recent study, and from a Foucauldian perspective, Bethany Lam (2008: 58-59) has discussed multiracialism in Light in August as a condition that favours reciprocal violence between the individual and the social order. The defiance that the multiracial represents to the visual discourse of race and to traditional racial boundaries is experienced by the societal forces in Faulkner's novel as a defiance to "the knowledge aspect of racial discourse, knowledge based on visual perception of skin color and the expectations created by the stereotypes themselves" (Lam 50). From this perspective, the images of disappearing or disfigured pictures used by Faulkner in the portrayal of Joe may be said to mirror the inaccessibility of identity for the multiracial Southern individual; the paradigm of the vanishing point is thus deployed as the technical counterpart to a cultural (Southern) attitude towards multiracialism as challenging the visibility of racial identity.

The functioning of the pictorial imagery as symbolically announcing Joe's disappearance produces a deliberate problematization of the character's end by complicating the relation between the connoted idea of disappearance and the event of Joe's death. Such complication attests to a kind of tension that informs the process of characterization in the Modernist narrative; the tension between the essentialist conception of character (in terms of self and personality) and the structuralist vision that defines character in terms of narrative function. This tension has also implications related to a kind of competition between the aestheticist and the representational paradigms within the Faulknerian narrative: Joe's disappearance allows for the highlighting of the impossibility of any sense 
of self attributed to or experienced by the character (Joe thus acquires his significance as a literary or aesthetic construct), while the scene of his death (his castration and his shooting) brings the kind of closure expected by the mimetic content of the character.

In Light in August also, the pictorial register of the vanishing point sustains the movement of the character (Joe Christmas) towards the condition of disappearance through his gradual association with the notion of the trace. Just before his violent death, Joe becomes sheer absence that is pointed to by the footprints left behind on the road; his occasional, unexpected reappearance rounds off his association with the vanishing point: Joe's status as a fugitive is rendered as an approximation of the similar fugitive condition that the vanishing point assumes in its instability and shifting (see Sorensen 434).

The tension in Light in August is one between the traditional and experimental matrixes of characterization, that is the tension is between the essentialist, identity-oriented process of character construction and the aestheticist orientation (with its focus on the aesthetic effect and construct of the work of art much more than on the mimetic content of characterization). That tension is firmly rooted in the crisis of representation, the questioning of the very possibility and limits of literary representation that the Modernists began to find inescapable. Many recent studies of narrative fiction have insisted on the difference between the implications and processes of characterization in Modernist and Postmodernist fiction. Among them, Gerhard Hoffmann (2005: 430-31) posits in his pertinent survey that the essentialist character-concept was complicated, rather than simply sustained, in the Modernist stream-ofconsciousness novel by the double focus on the temporal element of movement and change in addition to the forces of consciousness (perceived as extending horizontally in terms of stream and time and vertically in layers of consciousness and unconsciousness). The essentialist character-concept is thus maintained in the Modernist novel through its focus on the quest for identity or authenticity. The reinvention of the patterns of relations between self and world through the Modernist focus on body consciousness is often counteracted by the emphasis on the inner world and the processes of consciousness with the consequent 
creation of isolated character (Hoffmann: 431). It is probably this tendency to highlight the significance of the inner world of consciousness that allowed the essentialist concept of character to survive in the Modernist novel.

And yet, in Light in August, we find illustrated the tendency of some Modernist novels to problematize the essentialist concept of character by denying the characters any inner consciousness (as with Lena Grove) or minimising the character's inner world. With Joe Christmas, inner thoughts or anguish are mediated by a rhetoric of the ghostly and the shadowy, which sustains the paradigm of the vanishing point in its challenging of the essentialist concept of character. Much of the experimental trend in Postmodern fiction builds upon the Modernist achievements as far as the problematization of character and representation is concerned.

The Vanishing Point as a Model for Questioning Character and Representation: "Mrs. Mean" by William Gass and The Locked Room by Paul Auster

Totalizing ideas like identity, meaning and self have constantly been undermined by Postmodern thought and literature, which had an immediate bearing on the handling of character concept in much of Postmodern fiction. The construction of character in terms of "interiorized self" by the Modernist novel has often been the target of the deconstructive strategies of Postmodern narrative fiction (Hoffmann 431). Part of the paradox that relates the Modernist experimentation with narrative conventions to the Postmodern one has to do with the fact that the amplification of the concept of self in Modernism (an amplification that Hoffmann describes in terms of "the liberation of psychic force from social and moral form") has made inevitable its disintegration in Postmodern fiction (Hoffmann 431-32).

With the Postmodern experimental fiction, the conception of character as individual is neither totally dissolved nor negated: it is rather problematized by being doubly dissociated from the possibility of 
knowledge and from the Modernist paradigm of depth psychology. The fragmentation and contingency that inform the process of characterization in Postmodern fiction enhance its undermining of the identity concept and its questioning of the possibility for literary representation to induce the credibility of the sense of self that fictional character is expected to embody or experience.

Thus, in Postmodern fiction the deconstruction of the conventional components of fictional narrativity means that character is often maintained in a challenging position; half way between the assumed individuality traditionally attributed to character (an individuality that seems to resist the dismantling of the concept of self) and the wish to confer upon this fictional category the ambiguity of the "unpresentable." In "Mrs. Mean" by William Gass and The Locked Room by Paul Auster, the paradoxical nature of the processes of characterization (the creation of character as individual and as the embodiment of the unpresentable or the postmodern sublime) is implemented through the disruptive use by both narratives of the optical and pictorial paradigms. In Gass's short story, like in Auster's novella, the pictorial category of the vanishing point that condenses the paradoxes of character portrayal is itself generated by one of two basic narrative strategies: the conflation of voyeurism on narrative point of view, or assigning a character's portrait to an explicit intertextual play.

In William Gass's short story "Mrs. Mean," the narrator's voyeuristic attitude is associated with his longing for an ideal idleness that he describes in terms of a condition in which he would be surrounded with scenes and pictures. The process of storytelling carried on by the unnamed narrator is totally identified with the situation of the voyeur spying on his neighbours, and is motivated by the narrator's wish to fill in the void of his life with visual pictures of the others' bodies and lives. Some critics have pointed to the narrator's obsession with thoughts about the body as betraying his own inertia and his lack of a sexual life (Schwerdtferger 2005: 183-184). In relation to the whole problematization of character in Gass's story, the narrator's voyeuristic approach may also be interpreted as implying a critique of two fictional conventions: the convention of the disembodied narrative voice and the portrayal of character in terms of 
action and consciousness.

The narrative strategy of "Mrs. Mean" ironically subverts both narrative conventions through the presentation of a narrator-character who nevertheless remains 'disembodied' (there is hardly any feature or action that situates him in the fictional world except his spying gaze at his neighbours) and through the amplified foregrounding of the body (the other characters' bodies) in the narrative focalization. Thus, the narratorcharacter of Gass's short story is deliberately constructed within an aesthetic and ontological impossibility: his lack of a body does not turn him into a Cartesian subject (that is, a self that could exist without a body). Indeed, within the Postmodern rehabilitation of the body and the Postmodern conception of the self as absence that depends on the body, the notion of disembodied self becomes impossible (cf. Sorensen 444). Hence, the paradoxical status of Gass's narrator as improbable character (a character who can be acknowledged only in negative terms) maintains in the whole process of storytelling the irony of self-questioning.

The paradox of characterization in "Mrs. Mean" relies also on the narrative's appropriation of the visual model of the vanishing point. The narrator is portrayed within the scope of a representational limit: as an individual character whose human-like status is systematically undermined by his functioning as a 'disembodied' voice, consequently, he is confined to the ambiguous borderline between presence and absence. Like the vanishing point, his 'presence' is acknowledged as a limit case of perception; we cannot get any closer to him (all the aspects that would mark his personality remain inaccessible to the reader because inexistent in the narrative). When the narrator tells us for instance how his neighbours noticed his spying attitude and then ended up becoming indifferent (even blind) to his activity, he condenses the whole paradox of his characterization in the metaphor of the marble eyes: "they began to treat my eyes like marbles and to parade their lives indifferently before me" (83-84). His voyeurism is acknowledged in the very attitude of denial that the neighbours adopt; the narrator-character is there but not readily accessible to either the other characters or the reader. The metaphor of the marble eyes, however, complicates the trope of the vanishing point by invoking another visual category: the station point. 
Indeed, the narrator's voyeuristic method in "Mrs. Mean" reinforces the problematization of character by enacting an overlapping in the narrative perspective itself between the optical notions of the vanishing point and station point. In the theory of perspective, the station point is the point from which sight emerges and which is not itself visible; the organic eye (classically perceived as a point, rather than structure) has for long been associated with the category of the station point ${ }^{\mathrm{ii}}$. In narrative fiction, the convention of narrative point of view has similarly fulfilled the function of the station point: the act of narration mediates what point of view makes accessible (to the narrator and reader) in the fictional world while the device itself (point of view) is not foregrounded in the narrative. The problematical appropriation of this pictorial notion in Postmodern narrative fiction was mediated by the investment of the notion of the station point that Ludwig Wittgenstein made in his theoretical reflection on the concept of self. ${ }^{\text {iii }}$ On the basis of an assumed analogy between the eye as station point and the self as a boundary to the world (rather than a constituent of the world; the self as a limit to the real), Wittgenstein assimilates the self to absence ${ }^{\text {iv }}$ : the self on which any human experience of presence depends is not itself present or visible, in the same way the eye as a source of perception is itself a limit to the visual field; "the point from which sight originates is not itself visible" (Sorensen 439).

In "Mrs. Mean," an immediate consequence to the functioning of the narrator as a disembodied voice reduced to the act of spying on others is his assimilation to the "station point," which further problematizes the mimetic dimension of his status as a character. The narrator is not totally reduced to an abstract voice: his suspicious voyeurism is noted by the neighbours, and yet their growing indifference to his presence and his spying is described in terms that reduce the narrator to his perception and then negate that perception: "they began to treat my eyes like marbles and to parade their lives indifferently before me" (83-4). The narrator's human-like individuality is thus reduced to the fixity of the station point while his voyeuristic account of the neighbours' lives acquires its significance exclusively from the distortion and perversity attributed to his point of view. The narrator's obsessive focus on Mrs. Mean, among all his 
neighbours, invites the reader to conceive of the female character as the exact opposite of the narrator: actually, the narrator's obsessive attention to Mrs. Mean's body, to her continuous movement and incessant activity betrays the perversity of his own longing for the opposite of his inertia and barren life.

The central ironic process in Gass's short story is created from the juxtaposed effects of observation and narration: the narrator's voyeuristic storytelling causes him to vacillate between disappearance and pseudolife. The narrator's focus on the decaying body of Mr. Wallace causes him (that is the narrator) to disappear in the void of the character's death-like condition: "His eyes were holes I fell in" (86), while his description of Mrs. Mean's activity in her garden and with her four children becomes a form of "life" for him: "Except in the case of Mrs. Mean. I am no representative of preternatural power. I am no image [...] I don't exist" (88). Thus, throughout the story the narrator tries to detect the signs of his own existence and his individuality in the obsessive scrutiny of Mrs. Mean's body, her activities, her constant movement in the garden. The imagery of war and fire used by the narrator to suggest the character's hostility towards the plants in her garden and her aggressive reactions towards her children create an image of Mrs. Mean as a devilish, demonic figure. Not only does the narrator's reliability become doubtful ("my description is emotionally right, metaphysically appropriate" (105)) but the absurd exaggeration that informs his storytelling becomes the only sign or trace of his existence. The absent self of the narrator (as a station point) is detected only in the effects or traces of the verbal and stylistic game of narration, and it is detected only as absence that longs for presence even through absurd stylistic exaggeration: the entrapment of the narrator in a "disembodied" condition maintains "under erasure" (to repeat a Derridian notion) his supposed status as character. Towards the end of the story, the narrator gets impatient with his own "absence": the narration ends with the revelation of his intention to act. The intended intrusion into the Means' house does not allow the narrator to acquire a sense of self or a form of presence; it rather associates him with the status of a hypothetical double or mirror to the main character (that is Mrs. Mean). The intended intrusion expresses the narrator's wish to be 
liberated from the status of the station point; the end of the story (that takes place before he could carry out that intention) suggests however that he could only move into an illusive experience of selfhood.

The articulation of character as a vanishing point through the conscious play of intertextuality and literary self-reflexivity may be illustrated by the third narrative in Paul Auster's The New York Trilogy: The Locked Room. The novella revolves around the endeavour and dilemma of the narrator, a journalist-reviewer of art works, who is asked by the wife of a former class-mate, Fanshawe, to read and decide about the fate of a large number of manuscripts left by her husband who has mysteriously disappeared a few months earlier. The first-person narrative develops as partly a movement towards potential self-knowledge that the narrator hopes to achieve through the reconstruction of the character of the absent Fanshawe and partly as a detective plot. The narrator finds himself investigating the equally mysterious reappearance of Fanshawe through the strange letters he receives ad that are signed by the missing character who, from his hiding position manipulates the whole course of action in which the narrator gets involved. The narrative of The Locked Room develops also as a vacillation between the attempt at reconstructing the character of the missing Fanshawe through the narrator's reminiscence (the recalled crucial moments of their past friendship during their childhood and early youth, through the traces encompassed by the manuscripts of the many literary writings that Fanshawe produced during his life and that he always refused to publish, and finally through the narrator's attempt to write Fanshawe's biography.

The narrative process in Auster's novella confines the character of Fanshawe to the ambiguous borderline between presence and absence (enacting thus the paradigm of the vanishing point), while the implicit intertextual game from which the character emerges sustains a deliberate confusion between self and other. Indeed, the character of Fanshawe is partly constructed as a parodic echo and a complicated version of Hawthorne's Wakefield (in the story with the same title) and partly an ironic repetition of the mysterious Peter Stillman of the first novel of the trilogy, City of Glass. The framing parodic intertextuality is replicated within the narrative of The Locked Room in a way that repeatedly subverts 
conventional characterization. The motif of disappearance in Hawthorne's narrative mediates the character's attempt at detecting the traces of the self in the wife's reaction to his assumed death. In Auster's parodic narrative, the motif is assigned a deliberate intensity since Fanshawe's planned disappearance is motivated by the character's wish to reach a selfhood rooted in the boundary between authorship and anonymity, while the narrator himself hopes to decipher a sense of self through his own involvement in Fanshawe's story (his task is meant to be a final assertion of Fanshawe's absence) and in its narration. The complication introduced by the parodying text is reflected in Auster's sustained challenging of the expected association between character and a sense of self through two strategies: a confusing overlapping between self and other deliberately maintained by the narrative method, and a repeated dissolution of a promised or glimpsed sense of self (attributed to a character) in the foregrounded world of textuality and of intertextuality, which constantly reminds the reader of the nature of character as a verbal construct.

The emphatic assertion of Fanshawe's presence in the opening of The Locked Room stands as an ironic reminder of the narrator's (and the narrative's) dependence on such assetion: "without him I would hardly know who I am" (236). As the narrative begins by turning the fact of Fanshawe's absence into an asserted presence, it flaunts the fictionality of the whole process of characterization. The ironic play on the boundary between presence and absence is significantly linked to the challenging of the frontier between self and other. When the narrator occupies the position of the narratee of the story of Fanshawe's disappearance, he experiences a similar form of disappearance: "as I write this now, I realize that even on that first day I had slipped through a hole in the earth" (23940). The implicit metaphor of the grave installs in the narrative the dichotomy of life and death (a variation on presence versus disappearance) in terms of a narrative, textual focus: the narrator's psychological experience of a form of death when he listens to Sophie telling him about her past life with Fanshawe may be accounted for by his shift to the position of the passive narratee (he is neither the storyteller nor the theme of storytelling). The same image of the grave will be repeatedly revisited in the narrative, but it will often be motivated by the narrator's 
attempt to delimit the contours of the self (his self) through the commonsensical opposition between life and death: his belonging to life as logically contrasted with the supposed death of Fanshawe (the image of the grave often points to the likeliness of that hypothesis). This appeal to commonsense in the narrator's attempt to assert a sense of self in its opposition to otherness through the dichotomy of presence and absence is, however, part of a whole narrative strategy that challenges the very concept of character by maintaining under erasure the binary opposites on which it has conventionally depended (self versus other; human-like versus artefact).

Thus, the narrator uses the image of resurrection or that of unearthing a dead body in relation to his experience of identity and in the portrayal of Fanshawe; the variations on the same metaphor sustain a pattern of interchangeability between self and other. In his comment on the sense of self that he would acquire by fulfilling the task of reading and assessing the huge body of manuscripts left by Fanshawe, the narrator admits: "the thought flickered through me that I could one day be resurrected in my own eyes" (245). The same task of reading and deciding about the fate of those manuscripts is also described through the image of unearthing a dead body: "I had been given the power to obliterate, to steal a body from its grave and tear it to pieces" (262). But the image of violating the sanctity of a dead body comes as a deliberate perversion of earlier personification of the manuscripts ("I hauled the two suitcases slowly down the stairs $[\ldots]$ they were as heavy as a man" (246)). Part of the ironic process of characterization in Auster's narrative relies on the narrator's handling of the textual realm created by the absent Fanshawe as a substitute to the character himself; the manuscripts do not only bear the traces of their absent creator but they repeatedly flaunt the nature of fictional character as a verbal construct. The pictorial paradigm of the vanishing point is thus implemented in the ironic tension generated by the competition between the construction of character as a familiar fictional category that invokes to the reader human-like individuality, and the deconstruction of that fictional element through the highlighting of its illusionary and artificial nature.

It is part of the narrative's self-irony that in his attempt to 
rediscover and present the character of Fanshawe, the narrator finds himself confronting the ambiguous boundaries of the self, his self ("I lost track of myself" (345)). when he tries to restore a conventional opposition between self and other, his effort is no less ironic: in the moments when the narrative occasionally reaches a stable distinction between self and other, the embodiment of "otherness" is no other than Fanshawe himself; the character who is supposed to be the center of the storytelling process. Moreover, when Fanshawe is associated with the "otherness" against which a sense of self is expected to be reached by the narrator, the latter emerges as the mere double or mirror of that absent protagonist: "Once I opened the suitcases, I would become Fanshawe's spokesman [...] To issue a death sentence was bad enough, but working for a dead man hardly seemed better" (262). The narrator's strategy of identifying the boundary between self and other in terms of an absolute gap between life and death turns out to be self-deceptive; the "death sentence" imposed on Fanshawe through the interpretation of his unexplained absence is discovered to be illusionary (as Fanshawe is revealed to be only and willingly hiding from his environment). In addition, and once the narrator dwells on the issue of that boundary (between self and other; life and death) from the angle of writing and publication, of textuality and books, the characters' positions in the scheme of opposites is suddenly reversed:

If Fanshawe's work had been any less than it was, my role would have been different- more important, perhaps more crucial to the outcome of the story. But as it was, I was no more than an invisible instrument. Something had happened, and short of denying it, short of pretending I had not opened the suitcases, it would go on happening [...] moving with a momentum of its own. (263, emphasis added)

The narrator is aware that disappearance or invisibility would be imposed on him when Fanshawe is resurrected through his own writings once published. The process of publication in which the narrator fills in the position of the agent while Fanshawe acquires the status of authorship complicates the whole dichotomy of presence and disappearance. Indeed, the issue of publication is once approached by the narrator as a game that could be manipulated: he begins to think about exploiting the good reception of Fanshawe's work to publish his own writings under the 
pseudonym of Fanshawe (279). Actually, this possibility reminds the reader of a basic fact in The Locked Room: that Auster's narrator is unnamed," like Gass's narrator in "Mrs. Mean." Hence, his whole meditation on identity, authorship and pen-names remains highly ironical and self-defeating, reminding us of the narrator's own artificial nature whose status as a fully active but unnamed character challenges the very opposition in character construction between embodiment and disembodiment.

Towards the end of the narrative, however, the narrator brings to the surface the intertextual game of the whole New York Trilogy by suggesting that he is the writer of the three novels. The consequently established relationship of identity between the narrator of City of Glass and that of The Locked Room displays an intrinsic link between Auster's ironic subversion of conventional characterization and his problematization of the issue of authorship. The narrator of City of Glass whose initial name is Daniel Quinn turns into a "Paul Auster"; a fictitious detective whose name is imposed on Quinn through the absurd situation of a wrong phone call. But in the intertextual play between the narratives of The New York Trilogy that subversive use of the author's name as part of the fictitious fabric of the plot is further complicated. When the narrator of The Locked Room identifies himself as the writer of the three narratives (City of Glass, Ghosts and The Locked Room) he rounds off the dispersal of the sense of identity he is expected to embody as a character: he assimilates himself to the real Paul Auster, but inevitably confuses himself with the fictitious Paul Auster of City of Glass; in both ways, the narrator completely reduces the sense of self to otherness (he cannot be the real Auster since a narrator is by definition different from the author, and the "Auster" of the first novel is only a mask accepted by the narrator as part of a game-like investigation). The deconstruction of conventional character is further sustained when Fanshawe as he "physically" (re)appears for the first time introduces himself as Peter Stillman (349) (the mysterious criminal in City of Glass). The intertextual game asserts the rule of interchangeability between characters as a process of reinventing character within the paradigm of a deliberate dissolution of the boundary between self and otherness. Intertextuality, fully integrated 
to the storytelling process, enacts in Auster's The Locked Room the verbal counterpart to the visual notion of the vanishing point: amplifying the 'presence' of character as a necessary component (even the center) of narrative fiction while flaunting its illusionary, artificial essence.

\section{Conclusion}

In the three narratives discussed here, Light in August, "Mrs. Mean" and The Locked Room, we may discern an aspect of continuity between the functioning of literary self-questioning in Modernist and Postmodernist fiction. In Faulkner's novel, like in the two Postmodern texts discussed after it, the appeal to the visual category of the vanishing point does not imply an approximation of the visual as an ideal of verisimilitude or plausibility in character portrayal. It rather sustains a moment of selfcritique as the experimental narrative consciously confronts the limits of literary representation.

However, the scope and intensity of such self-critique become more conspicuous with Postmodern fiction. What may be deduced from the above analysis of Gass's and Auster's narratives is that in the Postmodern aesthetics of literary self-questioning, the problematical nature of literary representation is fully assumed and flaunted from within the process of storytelling. The pictorial paradigm of the vanishing point is invested not simply to redefine fictional character but to challenge its very concept. What is involved in such challenge is not only the undermining of conventional "disembodied" character (character associated with consciousness and depth psychology, while the bodily dimension is disregarded), but equally the notion of "embodiment." The Body, like consciousness or the psyche, is not readily available to an unproblematical representation, because representation in the first place is no longer understood as a "transparent" process of mirroring. Therefore, in "Mrs. Mean," like in The Locked Room the subversion of character is mainly enacted as a process of dwelling on the borderline between opposites (presence and absence; disembodiment and an obsessive focus on the body); the concept of character can survive, those narratives seem to say, only in the unsolved tension of appropriation and deconstruction. 


\section{Notes:}

i I am relying here on the concept of the "unpresentable" or the "Postmodern sublime" as developed by Lyotard in his theorizing of Postmodernism: "The postmodern would be that which, in the modern, puts forward the unpresentable in presentation itself; that which denies itself the solace of good forms, the consensus of a taste which would make it possible to share collectively the nostalgia for the unattainable; that which searches for new presentations, not in order to enjoy them but in order to impart a stronger sense of the unpresentable" (149). The "unpresentable" thus, is that disruption that challenges and questions presentation and literary (and more generally linguistic) representation from within its processes.

${ }^{i i}$ Sorensen accounts for this vision of the organic eye as a station point by the long-established definition of the eye as a point rather than a complex structure (439). He points to the persistence of this classical approach to the eye in the appeal to the pictorial realm made by the philosophical explorations of the concepts of self and identity.

iii See in particular Tractatus Logico-Philosophicus, where in answering his question about the location of the self or the metaphysical subject, Wittgenstein posits: "this is exactly like the case of the eye and the visual field. But really you do not see the eye. And nothing in the visual field allows you to infer that an eye sees it" (5.633).

iv Cf. Roy Sorensen, "The Vanishing Point...," pp. 438-439: he explains Wittgenstein's analogy between the eye and the self as the basis the conception of the self in terms of absence (or invisibility) on which any form of presence in the human experience depends.

${ }^{v}$ Cf. Steven C. Alford who discusses the issue of naming (its subversive use or absence) in The New York Trilogy as a main device in problematizing the theme of self-identity and in conflating the question of identity with that of textuality (see "Mirrors of Madness: Paul Auster's The New York Trilogy," mainly pp. 2729).

\section{Works cited:}

Auster, Paul. The Locked Room. [1986] The New York Trilogy. London: Penguin Books, 1990. 233-371.

Alford, Steven E. "Mirrors of Madness: Paul Auster's The New York Trilogy." Critique XXXVII, ${ }^{\circ} 1$ (Fall 1995): 17-33.

Babb, Genie. "Where the Bodies are Buried: Cartesian Dispositions in Narrative Theories of Character." Narrative 10, $\mathrm{n}^{\circ} 3$ (October 2002): 195-221.

Faulkner, William. Light in August [1932]. Middlesex \& New York: Penguin Books in association with Chatto \& Windus, 1983.

Gass, William. "Mrs. Mean." In the Heart of the Heart of the Country and Other Stories. New York: Harper \& Row, 1958. 80-119. 
Hoffmann, Gerhard. From Modernism to Postmodernism. Concepts and Strategies of Postmodern American Fiction. New York \& Admsterdam: Rodopi, 2005.

Kunin, Aaron. "Character Lounge." Modern Language Quarterly 70, n³ (September 2009): 291-317.

Lam, Bethany L. "Light in August in Light of Foucault: Reexamining the Biracial Experience." Arizona Quarterly 64, n 4 (Winter 2008): 49- 68.

Lyotard, Jean François. "Answering the Question: What is Postmodernism?" Modernism/Postmodernism. Ed. by Peter Brooks. London \& New York: Longman, 1992.

Phillips, Brian. "Character in Contemporary Fiction." The Hudson Review 56, n 4 (Winter 2004): 629- 642.

Schwerdtfeger, Barbara. Ethics in Postmodern Fiction. Donald Barthelme and William Gass. Heidelberg: Universitätsverlag Winter, 2005.

Sorensen, Roy. "The Vanishing Point: A Model of the Self as Absence." The Monist 90, n॰3 (2007): 432- 456.

Wittgenstein, Ludwig. Tractatus Logico-Philosophicus. Oxford: Basil Blackwell, 1969. 